ARTICLE

\title{
Elucidating heterogeneous photocatalytic superiority of microporous porphyrin organic cage
}

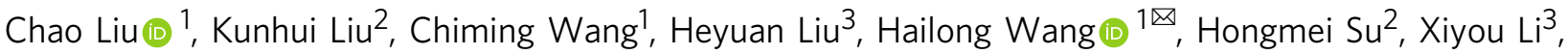 \\ Banglin Chen (i) ${ }^{4 凶} \&$ Jianzhuang Jiang (i) ${ }^{1 凶}$
}

The investigation on the catalytic properties of porous organic cages is still in an initial stage. Herein, the reaction of cyclohexanediamine with 5,15-di[3',5'-diformyl(1,1'-biphenyl)]porphyrin affords a porphyrin tubular organic cage, PTC- $1(2 \mathrm{H})$. Transient absorption spectroscopy in solution reveals much prolonged triplet lifetime of PTC- $1(2 \mathrm{H})$ relative to monomer reference, illustrating the unique photophysical behavior of cagelike photosensitizer. The long triplet lifetime ensures high-efficiency singlet oxygen evolution according to homogeneous photo-bleach experiment, electron spin-resonance spectroscopy, and aerobic photooxidation of benzylamine. Furthermore, microporous supramolecular framework of PTC-1 $(2 \mathrm{H})$ is able to promote the heterogeneous photo-oxidation of various primary amines with conversion efficiency above $99 \%$ under visible light irradiation. These results indicate the great application potentials of porous organic cages in heterogeneous phase.

\footnotetext{
${ }^{1}$ Department of Chemistry, Beijing Key Laboratory for Science and Application of Functional Molecular and Crystalline Materials, University of Science and Technology Beijing, Beijing 100083, China. ${ }^{2}$ College of Chemistry, Beijing Normal University, Beijing 100875, China. ${ }^{3}$ School of Materials Science and Engineering, China University of Petroleum (East China), Qingdao 266580, China. ${ }^{4}$ Department of Chemistry, University of Texas at San Antonio, San

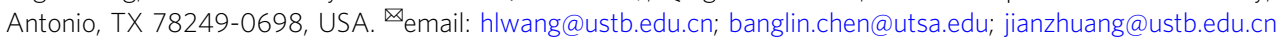


$\mathrm{V}$ isible light photocatalysis provides a green and sustainable approach for the synthesis of valuable organic chemicals by conceptually harnessing solar energy ${ }^{1-6}$, though it is still a great challenge to directly convert visible light to chemical energy because of the lack of absorption in this visible light region for most organic compounds. It has been established that the excited triplet states of some visible light-absorbing molecules are able to initiate the catalytic cycle via photo-induced electron/ energy transfer process ${ }^{1-6}$. By virtue of the strong visible light absorption, long triplet lifetime, and high triplet quantum yield, porphyrin derivatives have been extensively utilized as one of the most powerful photocatalysts toward aerobic organic reactions ${ }^{7-18}$. Their practical applications have been retarded by aggregation-induced deactivation of photosensitized performance and low-density solar energy ${ }^{5,15}$; it is therefore of great importance to develop excellent molecular porphyrin photocatalysts with improved absorption and excited states for facilitating photon conversion.

Molecular cages such as metal-organic coordination cages and porous organic cages are fabricated from discrete modules mainly depending on coordination and covalent bonds, respectively ${ }^{19-49}$. These unique synthetic hosts with well-defined cavities are capable of offering diverse weak interactions to recognize and encapsulate organic substrates ${ }^{46}$, constrain their orientations ${ }^{47}$, stabilize intermediates ${ }^{48}$, and mediate reaction kinetics, and thus used for their diverse applications ${ }^{49}$. Although the enzyme-like catalytic activities have been revealed for such special hosts by grafting/post-trapping catalytically active sites on cage skeletons or in cavities, respectively $25,44,45,50-52$, visible light photocatalytic molecular cages toward organic reactions have been still very rarely realized because of the low quantum yield of excited states attributed to the cage-induced self-quenching effect ${ }^{23,53-55}$. It has been envisioned that the ultrafast photo-induced energy/electron communication between hosts and cavity-confined guests in a close distance ${ }^{23}$ may facilitate the rapid conversion of reaction reagents. In addition, the supramolecular frameworks of molecular cages will possess not only the intrinsic intracage cavities but also the intercage porosities ${ }^{19,27,34}$, providing a renewable platform for heterogenizing homogeneous photocatalysts. With these considerations in our mind, we plan to develop visible light photocatalytic molecular cages constructed from porphyrin building units for their photo-induced heterogeneous catalysis.

In the present work, a $[3+6]$ porous tubular organic cage consisting of three porphyrin units, PTC-1 $(2 \mathrm{H})$, has been constructed and characterized by single crystal X-ray diffraction analysis. Transient absorption spectroscopy in solution reveals its prolonged triplet lifetime relative to porphyrin monomer, ensuring this kind of porphyrin molecular cage to efficiently promote the visible light-driven evolution of reactive oxygen species (ROS) and thus the aerobic photo-oxidation of benzylamine in homogeneous phase. Furthermore, such prominent molecular photocatalytic activity, in combination with the porous structure of the cage-based supramolecular framework, renders the solid PTC- $1(2 \mathrm{H})$ to exhibit $2-5$ times faster reaction rate in heterogeneous visible light catalysis of the aerobic photooxidation of primary amines than the reference monomer solid and two well-known porphyrin-containing metal-organic frameworks (MOFs), PCN-222 and PCN-224. These results disclose the great application potential of porous organic cages in visible light heterogeneous photocatalysis.

\section{Results}

Synthesis of porphyrin organic cage PTC-1(2H). Inspired by the pioneering work of Cooper and co-workers on fabricating the $[3+6]$ porous organic cages including TCC1, TCC2, and TCC $3^{56}$, a tubular organic cage, PTC-1 $(2 \mathrm{H})$, composed of porphyrin units was designed through the synthesis pathway (Fig. 1). To direct the synthesis, theoretical simulation over the reaction between metalfree 5,15-di[3',5'-diformyl-(1,1'-biphenyl)]porphyrin $\left(\mathrm{H}_{2} \mathrm{DBPP}\right)$ and cyclohexanediamine was carried out, giving a formation energy of $-79 \mathrm{kcal} \mathrm{mol}^{-1}$ for the metal-free porphyrin organic cage (Supplementary Data 1), consolidating the synthetic feasibility of PTC-1(2H) from thermodynamics by means of such a reaction

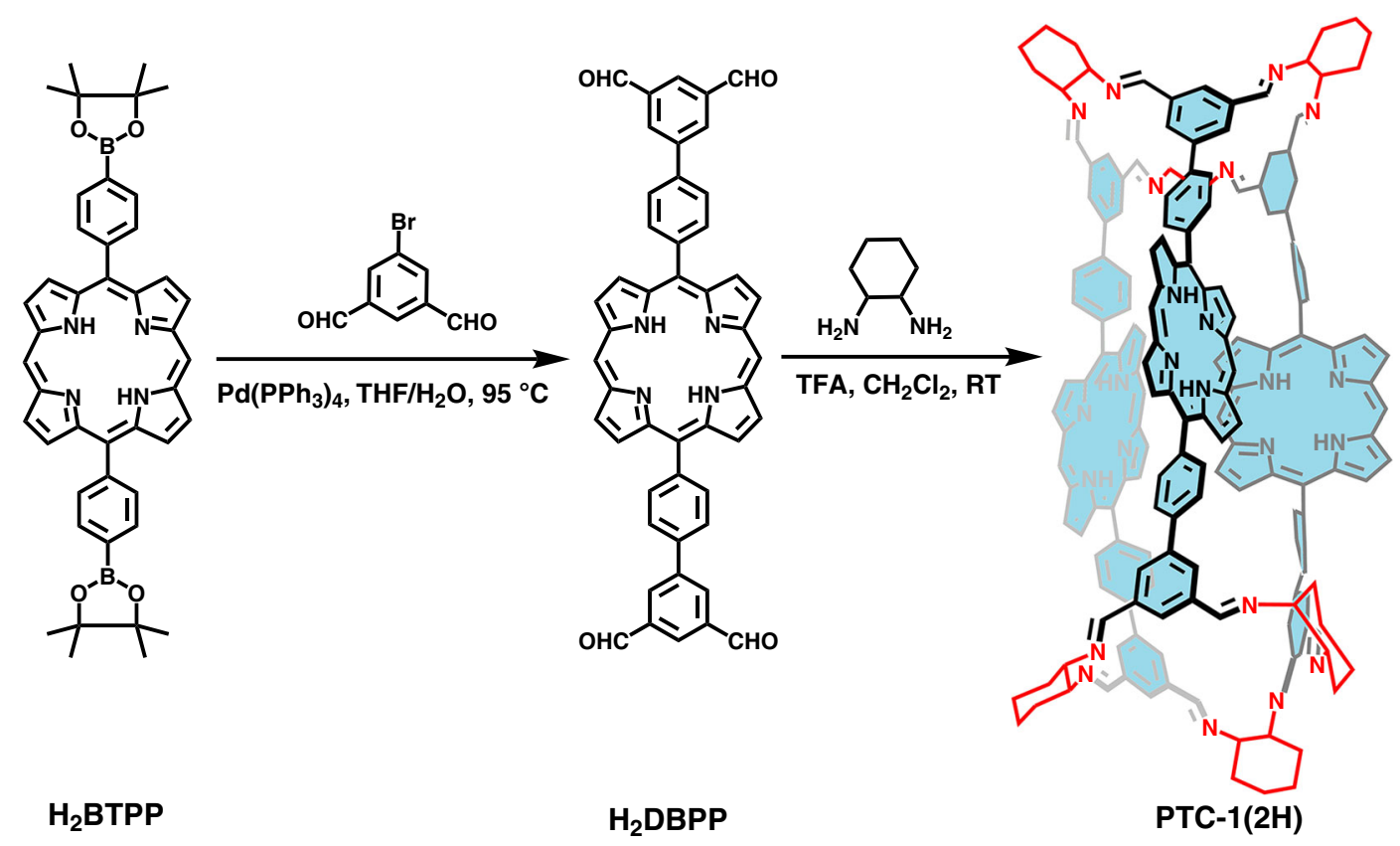

Fig. 1 Synthesis of tubular porphyrin organic cage. The synthetic route of PTC- $1(2 \mathrm{H})$ includes Suzuki-Miyaura cross-coupling between 5bromoisophthalaldehyde and 5,15-bis[4-(4,4,5,5-tetramethyl-1,3,2-dioxaborolan-2-yl)phenyl]porphyrin $\left(\mathrm{H}_{2} \mathrm{BTPP}\right)$ together with imine condensation reaction of enantiomerically pure cyclohexanediamine with 5,15-di[3', $5^{\prime}$-diformyl-(1,1'-biphenyl)]porphyrin $\left(\mathrm{H}_{2} \mathrm{DBPP}\right)$. 
route; for details, please see Supplementary Information. Subsequent reaction of $\mathrm{H}_{2} \mathrm{DBPP}$ with enantiomerically pure cyclohexanediamine afforded two enantiomers of PTC-1 $(2 \mathrm{H})$ in a good yield of $>85 \%$ with the help of trifluoroacetic acid as catalyst. This cage and a monomeric metal-free 5,15-di[3',5'-cyclohexyliminomethyl-1,1'-biphenyl]porphyrin $\left(\mathrm{H}_{2} \mathrm{CBPP}\right)$ were characterized by a series of spectroscopic methods, including nuclear magnetic resonance (NMR), ultraviolet-visible, circular dichroism, and mass spectroscopy (Table 1 and Supplementary Figs. 1-12 and Supplementary Table 1).

\begin{tabular}{|c|c|c|c|c|c|c|}
\hline \multirow[t]{2}{*}{ Compound } & \multirow{2}{*}{\multicolumn{2}{|c|}{$\begin{array}{l}\text { UV/vis spectra } \\
\text { in toluene } \\
\lambda_{\max }(\mathrm{nm})\end{array}$}} & \multicolumn{4}{|c|}{ fluorescence spectra in toluene } \\
\hline & & & $\lambda_{\text {ex }}(\mathrm{nm})$ & $\lambda_{\text {em }}(\mathrm{nm})$ & $\tau$ (ns) & $\varphi(\%)$ \\
\hline PTC-1(2H) & $\begin{array}{l}397,506 \\
580,635\end{array}$ & 542 & 405 & 638,702 & 9.80 & 1.82 \\
\hline $\mathrm{H}_{2} \mathrm{CBPP}$ & $\begin{array}{l}412,504 \\
579,635\end{array}$ & 540 & 405 & 638,700 & 9.87 & 1.86 \\
\hline \multirow[t]{2}{*}{ Compound } & \multicolumn{2}{|c|}{$\begin{array}{l}\text { CV spectraa } \\
\text { (vs. SCE) }\end{array}$} & \multicolumn{4}{|c|}{ TA spectra in toluene } \\
\hline & $\operatorname{Red}_{1}(V)$ & $\operatorname{Oxd}_{1}(V)$ & $\begin{array}{l}\text { TA ban } \\
\text { in } N_{2}\end{array}$ & d (nm) & $\tau(\mu \mathrm{s})^{b}$ & $\tau(\mu \mathrm{s})^{c}$ \\
\hline PTC-1(2H) & -0.97 & 0.98 & $430-50$ & & 102.20 & 0.33 \\
\hline $\mathrm{H}_{2} \mathrm{CBPP}$ & -0.98 & 1.10 & $425-50$ & & 53.98 & 0.25 \\
\hline
\end{tabular}

Molecular and supramolecular structures of PTC-1(2H). Purple cubic single crystals of this pair of enantiomers suitable for $\mathrm{X}$-ray diffraction analysis were obtained by diffusing methanol into the chloroform solution of the corresponding compound. The crystal structures of both enantiomers, $(R)-\mathrm{PTC}-1(2 \mathrm{H})$ (Fig. 2) and (S)-PTC-1(2H) (Supplementary Fig. 13), were determined by X-ray diffraction analysis. Both isostructural enantiomers crystallize in the trigonal system with a chiral R32 space group (Supplementary Table 2), showing six cage molecules per unit cell. Figures $2 \mathrm{a}$ and $2 \mathrm{~b}$ display the molecular structure of $(R)$-PTC- $1(2 \mathrm{H})$ as representative in side view and top view, respectively. Each cage molecule is composed of 3 porphyrin segments and 6 cyclohexanediimine groups linked by 12 imine bonds, forming a tubular structure with the length of $3.3 \mathrm{~nm}$, which appears to represent one of the longest molecular tube ${ }^{19-55}$. For each cage molecule, the separation of mesopositional $\mathrm{H}$ atom of each porphyrin unit to the $\mathrm{N} 4$ mean plane of neighboring porphyrin unit amounts to $2.8510(8) \AA$, indicating the presence of intramolecular $\mathrm{C}-\mathrm{H}-\pi$ interaction. As shown in the packing diagram for (R)-PTC-1(2H) (Fig. $2 \mathrm{c}, \mathrm{d}$ ), the neighboring molecular organic cages are packed into a onedimensional supramolecular tube depending on Van der Waals force, which are further packed into a three-dimensional porous supramolecular framework depending on Van der Waals interactions as well. In particular, neither intramolecular nor intermolecular neighboring porphyrin units have been arranged in a face-to-face packing mode in the porous cage-based supramolecular framework, enabling the solid sample to exhibit excellent heterogeneous photocatalytic properties through overcoming the general aggregation-induced photocatalyst deactivation for porphyrin materials. It is worth noting that, due to the isostructural nature of PTC-1 $(2 \mathrm{H})$ enantiomers, subsequent measurements were carried out only on $(R)$-PTC-1 $(2 \mathrm{H})$.

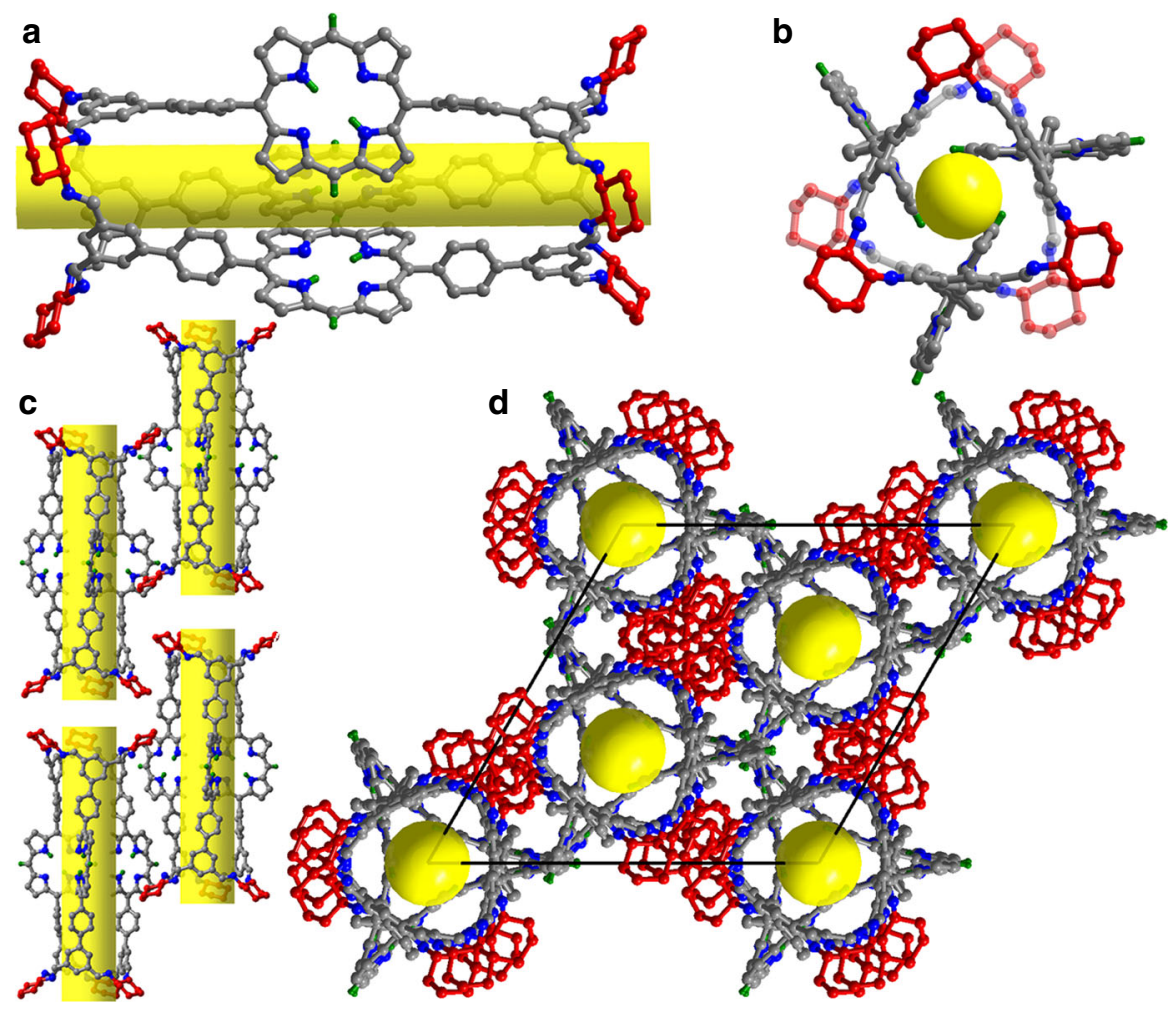

Fig. 2 Single crystal structure of molecular organic cage (R)-PTC-1(2H). a Side view and $\mathbf{b}$ top view; $\mathbf{c}$ window-to-window stacking mode of neighboring molecular organic cages; d packing profile along the direction of [001] (porphyrin $\mathrm{C}$, gray; cyclohexanediamine $\mathrm{C}$, red; $\mathrm{N}$, blue; $\mathrm{H}$, green; yellow tubes and balls represent the open one-dimensional channel and window, respectively; all selected hydrogen atoms omitted for clarity). 


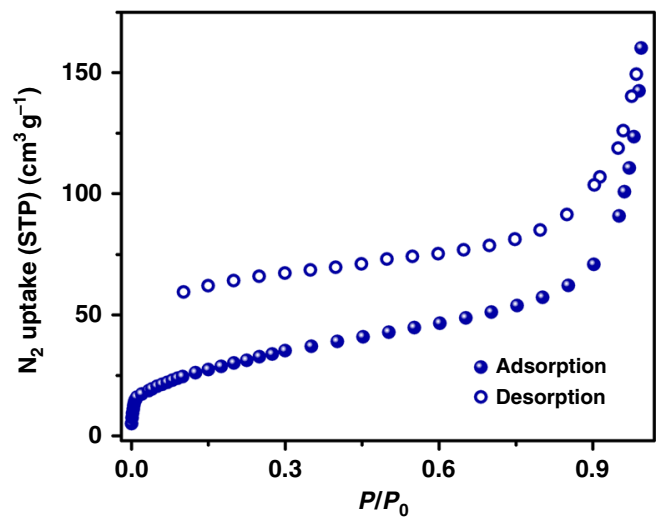

Fig. $3 \mathbf{N}_{\mathbf{2}}$ sorption isotherms of PTC-1(2H) at $\mathbf{7 7} \mathbf{K}$. Source data are provided as a Source Data file.

Permanent porosity of PTC-1(2H). $\mathrm{N}_{2}$ sorption experiment at $77 \mathrm{~K}$ was conducted to identify the permanent porosity of cagebased framework. PTC-1 $(2 \mathrm{H})$ shows a typical type I gas sorption behavior with the Brunauer-Emmett-Teller surface area of 112 $\mathrm{m}^{2} \mathrm{~g}^{-1}$ (Fig. 3). The large pore size of 1.35 and $2.73 \mathrm{~nm}$ for PTC-1 $(2 \mathrm{H})$ would benefit the small molecule diffusion during catalytic process (Supplementary Fig. 14). In addition, the powder X-ray diffraction pattern of the degassed cage-based framework matches well with that of the as-prepared sample, indicating the robust PTC-1 $(2 \mathrm{H})$ supramolecular framework (Supplementary Fig. 15).

Photophysical behaviors of PTC-1(2H). The molecular photophysical behaviors for PTC-1 $(2 \mathrm{H})$ were studied via electronic absorption, fluorescence, and transient absorption (TA) with monomeric $\mathrm{H}_{2} \mathrm{CBPP}$ as reference. PTC- $1(2 \mathrm{H})$ in toluene exhibits a typical electronic absorption spectrum for metal-free porphyrin chromophores with a strong Soret band at $397 \mathrm{~nm}$ and four weak $\mathrm{Q}$ bands at 506, 542, 580, and $635 \mathrm{~nm}$ (Table 1 and Supplementary Fig. 8). Only the Soret band of PTC-1(2H) takes a big blue-shift of $15 \mathrm{~nm}$ in comparison with that of $\mathrm{H}_{2} \mathrm{CBPP}(412 \mathrm{~nm})$ due to the presence of weak intramolecular $\mathrm{C}-\mathrm{H}-\pi$ interaction as revealed in the structure section. In $\mathrm{CH}_{2} \mathrm{Cl}_{2}$ and dimethylformamide (DMF), the Soret band and four Q bands of PTC-1 $(2 \mathrm{H})$ and $\mathrm{H}_{2} \mathrm{CBPP}$ almost do not change (Supplementary Fig. 8 and Supplementary Table 3).

Upon the excitation at $405 \mathrm{~nm}$, a broad split emission band peaking at 638 and $702 \mathrm{~nm}$ was observed for PTC-1(2H) in toluene with an absolute quantum yield of $1.82 \%$ and a lifetime of 9.80 ns (Table 1 and Supplementary Figs. 16-19 and Supplementary Table 3$)$. Both the fluorescence quantum yield and lifetime of PTC-1 $(2 \mathrm{H})$ are lower than those for $\mathrm{H}_{2} \mathrm{CBPP}$, namely, $1.86 \%$ and $9.87 \mathrm{~ns}$, respectively, due to the presence of much faster nonradiative and intersystem crossing process within the organic cage $^{57}$. Similar phenomenon was also observed in the emission of PTC-1 $(2 \mathrm{H})$ and $\mathrm{H}_{2} \mathrm{CBPP}$ in $\mathrm{CH}_{2} \mathrm{Cl}_{2}$ and DMF, respectively, Supplementary Table 3.

Toward understanding the relaxation process of the organic cage, nanosecond TA spectroscopy under the irradiation of the $355 \mathrm{~nm}$ laser pulse was employed. It is worth noting that, before the measurements, the concentration of porphyrin photosensitizers, including PTC-1 $(2 \mathrm{H})$ and $\mathrm{H}_{2} \mathrm{CBPP}$ reference, was adjusted to keep the same absorption intensity $(0.3)$ at $355 \mathrm{~nm}$. In nitrogen atmosphere, PTC-1 $(2 \mathrm{H})$ displays the negative absorption band in the range of $370-430 \mathrm{~nm}$ due to the typical ground-state bleaching of porphyrin core (Fig. $4 \mathrm{a})^{10,58}$. The positive bands observed at $430-500 \mathrm{~nm}$ are attributed to the characteristic porphyrin triplet absorption ${ }^{10,58}$. This is also true for the monomeric reference $\mathrm{H}_{2} \mathrm{CBPP}$ with ground-state bleaching and triplet bands observed at 380-425 and 425-500 nm (Supplementary Fig. 20). It is worth noting that the triplet quantum yield for either PTC-1 $(2 \mathrm{H})$ or $\mathrm{H}_{2} \mathrm{CBPP}$ could not be quantitatively evaluated owing to the overlapping between their triplet band and ground-state bleaching band, Fig. 4a and Supplementary Fig. $20 \mathrm{a}^{59}$. The similar triplet quantum yield for PTC-1 $(2 \mathrm{H})$ to that of $\mathrm{H}_{2} \mathrm{CBPP}$, however, is qualitatively unveiled by their similar absolute fluorescence quantum yield and lifetime ${ }^{60}$, while the triplet lifetime $(102.20 \mu \mathrm{s})$ for this cage is almost twice longer than that of monomer $(53.98 \mu \mathrm{s})$, which is associated with the much more rigid structure of the cage molecule (Fig. $4 \mathrm{~b})^{61}$. This result suggests the existence of much more reaction opportunities between the triplet excited states of cages and ${ }^{3} \mathrm{O}_{2}$ molecules, being helpful for the photo-inducing evolution of ROS. The TA spectra of PTC-1(2H) in air are shown (Supplementary Fig. 21). Both ground-state bleaching and triplet absorption bands did not show any obvious shift. The triplet lifetime of PTC-1 $(2 \mathrm{H})$ got seriously shortened to $0.33 \mu \mathrm{s}$, in comparison to that in $\mathrm{N}_{2}$, $102.20 \mu \mathrm{s}$, due to the reaction occurring between the triplet excited states of porphyrin organic cages and $\mathrm{O}_{2}$ dissolved in solution (Table 1 and Supplementary Fig. 22).

Homogeneous photocatalytic property of PTC-1(2H). Prior to evaluating their visible light photocatalytic activity toward ROS evolution, the electrochemical behavior for PTC-1 $(2 \mathrm{H})$ was studied. Electrochemical measurement result reveals the similar reduction potential of $-0.97 \mathrm{~V}$ for PTC- $1(2 \mathrm{H})$ to $-0.98 \mathrm{~V}$ for $\mathrm{H}_{2} \mathrm{CBPP}$ due to the very weak intracage interaction as disclosed by theoretically calculated frontier molecular orbitals (Table 1 and Supplementary Figs. 23 and 24). The higher reduction potentials of these samples than the reduction potential $-0.56 \mathrm{~V}$ (vs. standard calomel electrode) for $\mathrm{O}_{2} / \mathrm{O}_{2}{ }^{--}$indicate the photocatalytic capacity of organic cage toward generating $\mathrm{O}_{2}{ }^{\bullet-62}$. This is verified by the subsequent time-dependent photo-bleach experiment based on the oxidation of 1,3-diphenylisobenzofuran (DPBF) by ${ }^{1} \mathrm{O}_{2}$ and $\mathrm{O}_{2}{ }^{--}$using PTC-1(2H) as photocatalyst in DMF solution under the visible light irradiation of $\lambda>510 \mathrm{~nm}$ (Fig. 4c and Supplementary Fig. 25) ${ }^{63}$. Nevertheless, PTC-1 $(2 \mathrm{H})$ shows much higher ROS (actually a total ${ }^{1} \mathrm{O}_{2}$ and $\mathrm{O}_{2}{ }^{\bullet-}$ ) generation efficiency than monomeric $\mathrm{H}_{2} \mathrm{CBPP}$ and a typical porphyrin representative of 5,10,15,20-tetraphenylporphyrin (TPP), illustrating the prominent homogeneous photocatalytic property of the cage-like photosensitizer (Fig. $4 \mathrm{~d}$ ). The higher quantum yield of singlet oxygen for PTC- $1(2 \mathrm{H})\left(\Phi_{\Delta}=0.93\right)$ than that for $\mathrm{H}_{2} \mathrm{CBPP}\left(\Phi_{\Delta}=0.87\right)$ in toluene was quantitatively measured on the basis of the typical emission with the center at ca. $1270 \mathrm{~nm}$ with TPP as reference $\left(\Phi_{\Delta}=0.70\right)^{64}$ (Supplementary Fig. 26). This, in cooperation with the similar quantum yield of triplet state for PTC-1 $(2 \mathrm{H})$ and $\mathrm{H}_{2} \mathrm{CBPP}$ unveiled in a qualitative manner as detailed above, confirms the crucial role of triplet lifetime in the photo-driven singlet oxygen evolution.

In addition, the electron spin-resonance (ESR) spectroscopy was also employed to further check the photocatalytic activities of PTC-1 $(2 \mathrm{H})$ with 2,2,6,6-tetramethylpiperidine (TEMP) and 5,5dimetyl-1-pyrroline $\mathrm{N}$-oxide (DMPO) as ${ }^{1} \mathrm{O}_{2}$ - and $\mathrm{O}_{2}{ }^{-{ }^{-}}$-sensitive probes, respectively ${ }^{63}$. The ESR spectra for either TEMP or DMPO trapping agents in the presence of photosensitizer including PTC-1 $(2 \mathrm{H})$ and three-equivalent $\mathrm{H}_{2} \mathrm{CBPP}$ kept almost silent before the irradiation of a blue light-emitting diode (LED) light $\left(420 \mathrm{~nm}<\lambda_{\mathrm{em}}<490 \mathrm{~nm}\right)$ (Supplementary Figs. 27 and 28). The irradiation led to an expected appearance of ESR signals for both TEMP and DMPO capturers, indicating the production of ${ }^{1} \mathrm{O}_{2}$ and $\mathrm{O}_{2}{ }^{\bullet-}$, respectively. In particular, the ESR signal intensity with the ${ }^{1} \mathrm{O}_{2}$ scavenger of TEMP over organic cage is significantly larger than the monomer-induced signal, confirming the 

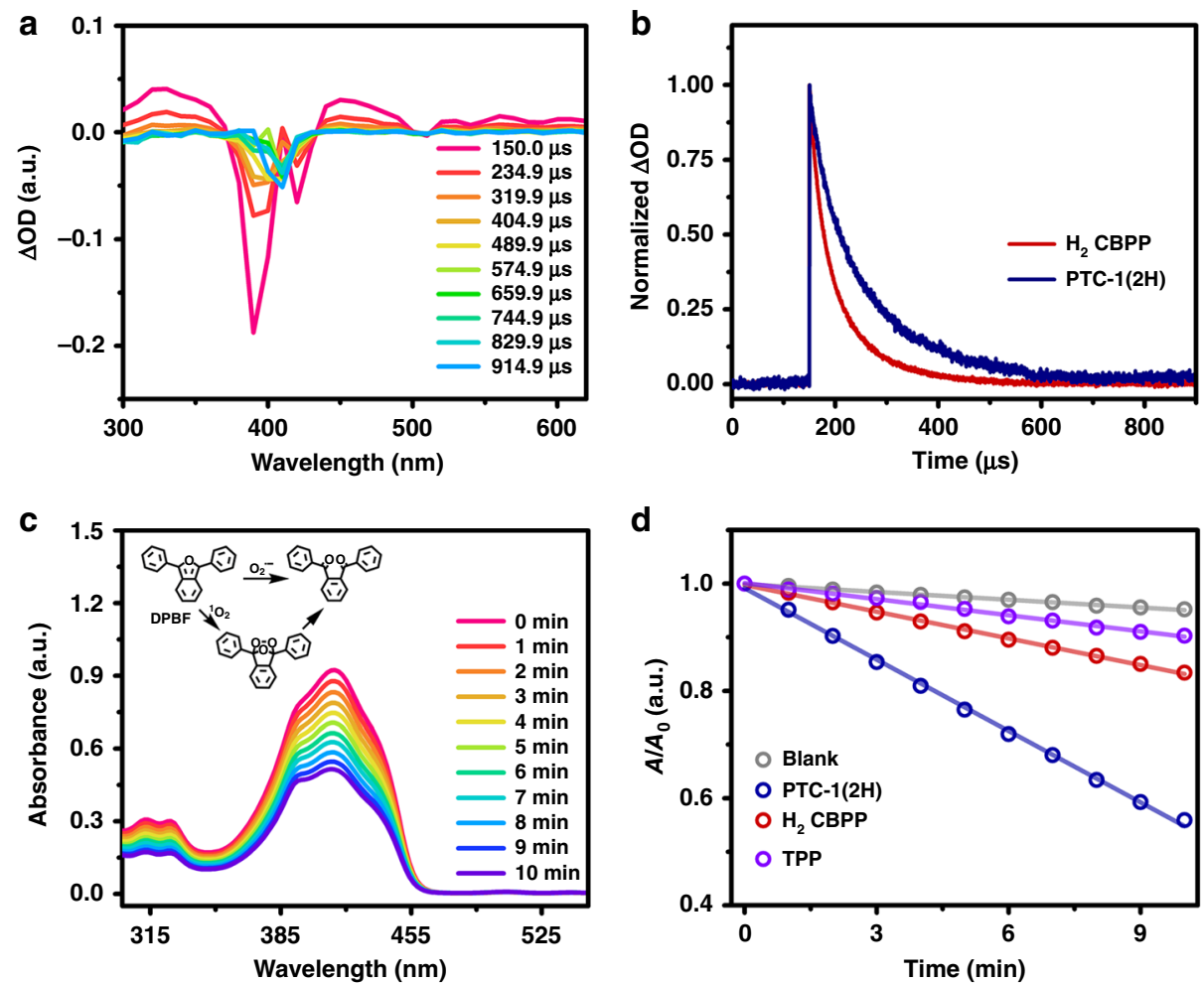

Fig. 4 Homogeneous photophysical and photocatalytic behaviors of PTC-1(2H). a Nanosecond transient absorption spectra for a toluene solution of PTC- $1(2 \mathrm{H})$ excited upon $355 \mathrm{~nm}$ laser pulse under nitrogen condition; $\mathbf{b}$ normalized kinetic traces of the $450 \mathrm{~nm}$ band of PTC-1 $(2 \mathrm{H})$ and $\mathrm{H}_{2} \mathrm{CBPP}$ under nitrogen condition; c time-dependent absorption spectra of DPBF in DMF upon visible light irradiation $(\lambda>510 \mathrm{~nm})$ in the presence of PTC- $1(2 \mathrm{H})$; d comparison of absorbance decay rate at $416 \mathrm{~nm}$ of DPBF in the presence of different catalysts. Source data are provided as a Source Data file.

outstanding visible light-driven homogeneous photocatalytic properties of PTC-1 $(2 \mathrm{H})$ in singlet oxygen evolution associated with the long triplet lifetime. In contrast, the similar $\mathrm{DMPO}-\mathrm{O}_{2}{ }^{--}$ ESR signal intensity monitored after addition of organic cage or monomer in a three-equivalent amount indicates their comparable visible light photocatalytic performance in terms of the $\mathrm{O}_{2}{ }^{--}$ evolution (Supplementary Fig. 28). As a total result, the cage triplet lifetime rather than the triplet state quantum yield dominates the present visible light-induced generation of ROS (mainly the singlet oxygen). This result must be helpful in the application of molecular cage in the field of photodynamic therapy and artificial photosynthesis.

Further evaluating the photocatalytic properties of PTC- $1(2 \mathrm{H})$, the oxidation coupling reaction of benzylamine with ${ }^{1} \mathrm{O}_{2}$ and $\mathrm{O}_{2}{ }^{\circ-}$ was studied under a blue LED light irradiation. In fact, selective oxidation of amine is of significance in the synthesis of biologically active imine derivatives ${ }^{65}$. With the help of cagebased photocatalyst and within a short time of ca. $15.0 \mathrm{~min},>99 \%$ benzylamine molecules have been converted into $\mathrm{N}$-benzylidenebenzylamine (based on the NMR data; Table 2). In contrast, a longer reaction time of 20.0 and $25.0 \mathrm{~min}$ becomes necessary for the monomer photocatalysts, $\mathrm{H}_{2} \mathrm{CBPP}$ and TPP, respectively, to convert $>99 \%$ benzylamine molecules to target product. This, in cooperation with the TA and ESR spectroscopic results as mentioned above, confirms not only the prominent photocatalytic performance of organic cage under visible light irradiation but also the long triplet lifetime-related promotion mechanism. In the control experiments with reaction exposed in air and in the absence of PTC- $1(2 \mathrm{H})$ photocatalyst, the conversion of benzylamine into $\mathrm{N}$-benzylidenebenzylamine either proceeded in much slower speed or kept unreacted, illustrating the crucial role of molecular cage-based photocatalyst and oxygen. Nevertheless, the

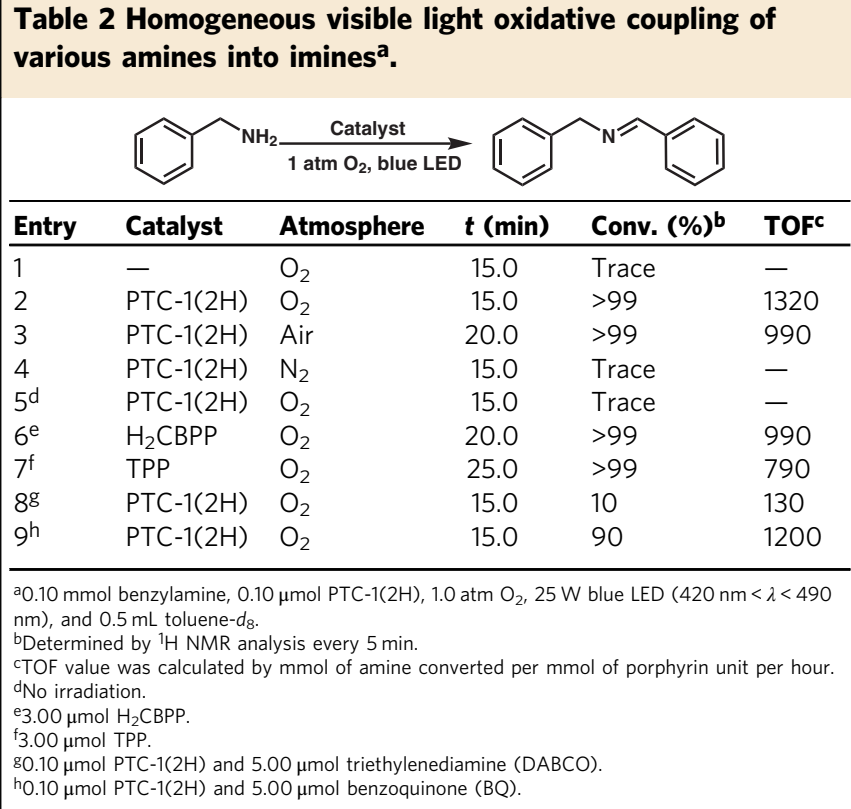

homogeneous control experiments in the presence of $5.00 \mu \mathrm{mol}$ triethylenediamine (DABCO) as an efficient singlet oxygen quencher and $5.00 \mu \mathrm{mol}$ benzoquinone $(\mathrm{BQ})$ as a trapping agent for $\mathrm{O}_{2}{ }^{--}$gave $9 \%$ and $90 \%$ conversion of benzylamine to the corresponding product, respectively (Table 2 ), indicating the more important role of singlet oxygen instead of $\mathrm{O}_{2}{ }^{--}$in the present reaction process. 

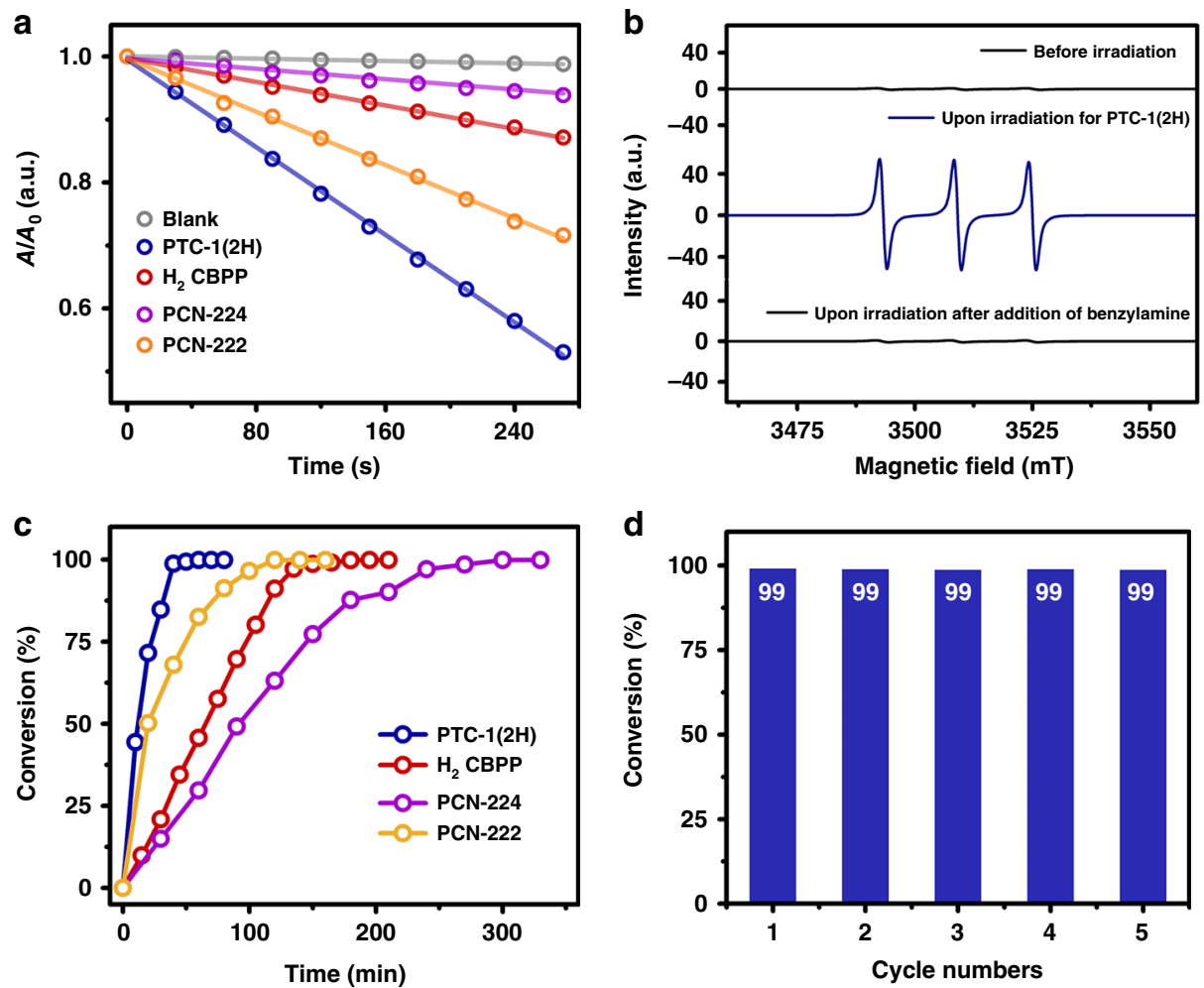

Fig. 5 Heterogeneous photocatalytic behavior of PTC-1(2H). a Comparison of absorbance decay rate at $410 \mathrm{~nm}$ of DPBF in the presence of different photocatalysts in $\mathrm{CH}_{3} \mathrm{CN}$ upon visible light irradiation of $\lambda>510 \mathrm{~nm}$; b ESR detection of ${ }^{1} \mathrm{O}_{2}$ generation over PTC-1(2H) trapped by TEMP in $\mathrm{CH}{ }_{3} \mathrm{CN}$; c comparison of time-dependent heterogeneous catalytic efficiency of different photocatalysts; $\mathbf{d}$ recycle test of PTC- $1(2 \mathrm{H})$ in the photo-induced oxidative coupling of benzylamine to $\mathrm{N}$-benzylidenebenzylamine. Source data are provided as a Source Data file.

Heterogeneous photocatalytic properties of PTC-1(2H). It is well known that the practical application of the molecular porphyrins as heterogeneous photocatalysts has been retarded by the aggregation-induced deactivation ${ }^{13,15}$. The lack of both the intramolecular and intermolecular face-to-face packed porphyrin moieties in the cage-based supramolecular framework as revealed by single crystal X-ray analysis, in combination with the existence of moderately permanent porosity in the PTC-1(2H) framework, therefore inspires our interest toward investigating its heterogeneous photocatalytic performance. For this purpose, the visible light-induced ROS evolution capability of crystalline PTC-1 $(2 \mathrm{H})$ sample in acetonitrile was examined first. For comparative studies, the ROS evolution activities of solid $\mathrm{H}_{2} \mathrm{CBPP}$ and two wellknown porphyrin-containing MOFs of PCN-222 (also known as MOF-545 or MMPF-6) ${ }^{66,67}$ and PCN-224 ${ }^{68}$ were also examined under the same concentration of porphyrin units and experimental conditions. The visible light-induced DPBF photo-bleach time-dependent curves reveal the highest ROS generation efficiency of the solid PTC-1(2H), verifying the expected excellent heterogeneous photocatalytic property of this cage-based supramolecular framework (Fig. 5a and Supplementary Fig. 29).

In addition, visible light-induced photo-oxidation of benzylamine by oxygen was chosen again as a heterogeneous catalytic model reaction. In the oxygen atmosphere, $>99 \%$ benzylamine in $\mathrm{CD}_{3} \mathrm{CN}$ could be converted into $N$-benzylidenebenzylamine within only $60 \mathrm{~min}$ with the help of PTC-1 $(2 \mathrm{H})$ supramolecular framework (Table 3). ESR spectroscopic data with TEMP and DMPO sensor, respectively, indicate the seriously reduced intensity of photo-induced signals after addition of benzylamine into the suspension of PTC-1(2H) supramolecular framework in
Table 3 Heterogeneous visible light oxidative coupling of various amines into imines ${ }^{a}$.

\begin{tabular}{|c|c|c|c|c|c|}
\hline Entry & Substrate & Product & $t$ (min) & Conv. $(\%)^{b}$ & TOFc \\
\hline 1 & $\mathrm{R}=\mathrm{H}$ & $\mathrm{R}=\mathrm{H}$ & 60 & $>99$ & 33.0 \\
\hline 2 & $\mathrm{R}=\mathrm{F}$ & $\mathrm{R}=\mathrm{F}$ & 50 & $>99$ & 39.6 \\
\hline 3 & $\mathrm{R}=\mathrm{CH}_{3}$ & $\mathrm{R}=\mathrm{CH}_{3}$ & 60 & $>99$ & 33.0 \\
\hline 4 & $\mathrm{R}=\mathrm{OCH}_{3}$ & $\mathrm{R}=\mathrm{OCH}_{3}$ & 70 & $>99$ & 28.2 \\
\hline 5 & $\mathrm{R}=\mathrm{Cl}$ & $\mathrm{R}=\mathrm{Cl}$ & 90 & $>99$ & 22.0 \\
\hline 6 & & & 50 & $>99$ & 39.6 \\
\hline 7 & & & 120 & $>99$ & 16.5 \\
\hline 8 & & & 140 & $>99$ & 14.1 \\
\hline $9^{d}$ & $\mathrm{R}=\mathrm{H}$ & $\mathrm{R}=\mathrm{H}$ & 180 & $>99$ & 11.0 \\
\hline $10^{\mathrm{e}}$ & $\mathrm{R}=\mathrm{H}$ & $\mathrm{R}=\mathrm{H}$ & 120 & $>99$ & 16.5 \\
\hline $11^{f}$ & $\mathrm{R}=\mathrm{H}$ & $\mathrm{R}=\mathrm{H}$ & 300 & $>99$ & 6.6 \\
\hline $12^{g}$ & $\mathrm{R}=\mathrm{H}$ & $\mathrm{R}=\mathrm{H}$ & 60 & 25 & 8.3 \\
\hline $13^{h}$ & $\mathrm{R}=\mathrm{H}$ & $\mathrm{R}=\mathrm{H}$ & 60 & 57 & 19.0 \\
\hline \multicolumn{6}{|c|}{ 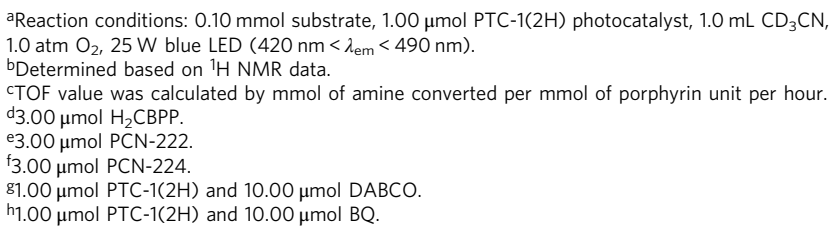 } \\
\hline
\end{tabular}


$\mathrm{CD}_{3} \mathrm{CN}$, disclosing the association of high-efficiency conversion of benzylamine with ${ }^{1} \mathrm{O}_{2}$ and $\mathrm{O}_{2}{ }^{--}$(Fig. $5 \mathrm{~b}$ and Supplementary Fig. 30) ${ }^{64}$. The heterogeneous control experiments in the presence of the same amount of DABCO and BQ gave $25 \%$ and $57 \%$ conversion of benzylamine, respectively (Table 3), further revealing the more important role of singlet oxygen in the present conversion upon cage photocatalyst. In the control experiments, much longer reaction time of 180,120 , and 300 min were needed for solid $\mathrm{H}_{2} \mathrm{CBPP}, \mathrm{PCN}-222$, and PCN-224, respectively, instead of PTC- $1(2 \mathrm{H})$ as heterogeneous photocatalyst to achieve $>99 \%$ conversion of benzylamine (Fig. $5 \mathrm{c}$ and Table 3 ), illustrating the best heterogeneous photocatalytic activity of PTC-1(2H) supramolecular framework among these species.

After the conversion of benzylamine, the PTC- $1(2 \mathrm{H})$ catalyst was separated from the reaction mixture in $\mathrm{CD}_{3} \mathrm{CN}$ and washed by $n$-hexane for three times to remove the residue chemical over the catalyst surface. ${ }^{1} \mathrm{H}$ NMR spectroscopic results recorded in $\mathrm{CD}_{3} \mathrm{CN}$ containing dispersed PTC- $1(2 \mathrm{H})$ catalyst then clearly reveal the release of $\mathrm{N}$-benzylidenebenzylamine from the pores of the heterogeneous catalyst (Supplementary Fig. 31), indicating the effective diffusion of product molecule from the pores within PTC-1 $(2 \mathrm{H})$ framework due to the big pore size. This might preclude the product inhibition effect ${ }^{49}$ and benefit the photoinduced benzylamine conversion. Nevertheless, the highly efficient and constant conversion of benzylamine under the photocatalysis of PTC-1 $(2 \mathrm{H})$ framework continues for five times, demonstrating the good recyclability of solid PTC- $1(2 \mathrm{H})$ catalyst (Fig. 5d).

For the purpose of revealing the general applicability of PTC$1(2 \mathrm{H})$ heterogeneous photocatalyst, the photo-oxidation of a series of primary amine derivatives was carried out. With the assistance of PTC- $1(2 \mathrm{H})$ supramolecular framework, the whole series of benzylamine derivatives substituted with different functional groups could be converted to corresponding products with $>99 \%$ conversion in a specified period, revealing the excellent properties of solid porphyrin organic cage PCT-1 $(2 \mathrm{H})$ as a heterogeneous photocatalyst (Table 3$)$. Among the diverse substrates, (4-fluorophenyl)methanamine converted to $\mathrm{N}$-(4-fluorobenzyl)-1-(4-fluorophenyl)methanimine within the shortest time of $50 \mathrm{~min}$ due to the electron-withdrawing effect of fluorine atom. This is also true for 3,4-difluorobenzylamine. In contrast, much longer time ranging from 90 and $120 \mathrm{~min}$ becomes necessary for the complete conversion of the chlorinesubstituted substrates including 4-chorobenzylamine and 3,4dichorobenzylamine to corresponding $N$-benzylidenebenzylamine derivatives due to the effect of the $p-\pi$ conjugation for chlorine atom ${ }^{69}$.

\section{Discussion}

A [3+6] metal-free porphyrin organic cage in a tubular structure with the length of $3.3 \mathrm{~nm}$ has been successfully fabricated and assembled into porous supramolecular framework. The cageinduced long triplet lifetime was revealed to play crucial role in the high-efficiency singlet oxygen evolution and in turn the photo-oxidation of benzylamine in homogeneous phase. More importantly, the porphyrin cage-based porous supramolecular framework overcomes the general aggregation-induced deactivation of molecular porphyrins as heterogeneous catalyst and efficiently promotes photo-oxidation coupling reaction of various primary amines. The present result discloses the unique catalytic activity of porous organic cages in heterogeneous photocatalysis associated with the unique cage-induced long triplet lifetime and porous structure, which is expected to ignite more research interest toward exploration of porous organic cage with great heterogeneous application potentials.

\section{Methods}

Remark. Dichloromethane was freshly distilled from $\mathrm{CaH}_{2}$. The other commercial chemicals were used without any further treatment. $\mathrm{H}_{2} \mathrm{DBPP}$ was prepared from the reaction between 5,15-bis[4-(4,4,5,5-tetramethyl-1,3,2-dioxaborolan-2-yl)phenyl]porphyrin ${ }^{70}$ and 5-bromoisophthalaldehyde. For details, please see Supplementary Information.

Synthesis of PTC-1(2H). To a suspension of $\mathrm{H}_{2} \mathrm{DBPP}(0.06 \mathrm{mmol})$ and trifluoroacetic acid $(2.0 \mu \mathrm{L})$ in dichloromethane $(50 \mathrm{~mL})$, a solution of enantiomerically pure cyclohexanediamine $(14.8 \mathrm{mg}, 0.130 \mathrm{mmol})$ in dichloromethane $(20 \mathrm{~mL})$ was added slowly. The mixture was stirred at room temperature for $24 \mathrm{~h}$. Then the reaction mixture was evaporated under reduced pressure and applied on a silica gel column using tetrahydrofuran as eluent. Repeated column chromatography followed by recrystallization in chloroform and methanol gave the target organic cages as dark red powder in the yield of $85.6 \%$ and $87.3 \%$ for $(R)$-PTC- $1(2 \mathrm{H})$ and (S)-PTC-1(2H), respectively. ${ }^{1} \mathrm{H}$ NMR $\left(400 \mathrm{MHz}, \mathrm{CDCl}_{3}\right): \delta 8.78(\mathrm{~d}, J=4.5 \mathrm{~Hz}$ $12 \mathrm{H}), 8.64(\mathrm{~d}, J=16.3 \mathrm{~Hz}, 12 \mathrm{H}), 8.54(\mathrm{~s}, 6 \mathrm{H}), 8.37(\mathrm{~d}, J=7.6 \mathrm{~Hz}, 12 \mathrm{H}), 8.23(\mathrm{~s}$, $6 \mathrm{H}), 8.16(\mathrm{~d}, J=7.7 \mathrm{~Hz}, 12 \mathrm{H}), 8.07(\mathrm{~s}, 6 \mathrm{H}), 7.75-7.45(\mathrm{~m}, 18 \mathrm{H}), 3.71(\mathrm{dd}, J=14.0$ $8.8 \mathrm{~Hz}, 6 \mathrm{H}), 3.57(\mathrm{dd}, J=15.4,8.5 \mathrm{~Hz}, 6 \mathrm{H}), 2.00(\mathrm{~d}, J=11.8 \mathrm{~Hz}, 24 \mathrm{H}), 1.70(\mathrm{~s}$, 24H), $-3.56(\mathrm{~s}, 6 \mathrm{H}) ;{ }^{13} \mathrm{C}$ NMR $\left(100 \mathrm{MHz}, \mathrm{CDCl}_{3}\right): \delta 160.67,160.31,146.71,144.34$, $141.13,141.02,139.18,137.44,137.19,135.18,132.51,131.32,130.04,125.63$, $118.11,104.50,75.66,74.99,33.27,32.81,29.70,24.68$; MS (MALDI-TOF) $\mathrm{m} / z:[\mathrm{M}]$ + calcd. for $\mathrm{C}_{180} \mathrm{H}_{150} \mathrm{~N}_{24}, 2649.25$; found: 2649.53 for $(R)$-PTC-1(2H) and 2649.34 for $(S)$-PTC-1(2H); analysis of $(R)$-PTC-1(2H) (calcd., found for

$\left.\mathrm{C}_{180} \mathrm{H}_{150} \mathrm{~N}_{24} \cdot 1.5 \mathrm{CHCl}_{3}\right)$ : $\mathrm{C}(77.07,76.96), \mathrm{H}(5.40,5.88), \mathrm{N}(11.89,11.66)$; analysis of $(S)$-PTC-1 $(2 \mathrm{H})$ (calcd., found for $\left.\mathrm{C}_{180} \mathrm{H}_{150} \mathrm{~N}_{24}\right)$ : C $(81.60,81.22), \mathrm{H}(5.70,5.44)$, $\mathrm{N}(12.69,12.87)$.

\section{Data availability}

The authors declare that the data supporting the findings of this study are available within the main manuscript and Supplementary Information. The source data underlying Figs. 3, 4a-c, and 5b, c and Supplementary Figs. 7-9, 14-22, 25, and 27-30 are provided as a Source Data file. Extra data are available from the corresponding author upon reasonable request. The crystallographic data in this study have been deposited in the Cambridge Structural Database under entry IDs CCDC 1913971 and 1913972. These data can be obtained free of charge from The Cambridge Crystallographic Data Centre via www.ccdc.cam.ac.uk/data_request/cif.

Received: 28 August 2019; Accepted: 31 January 2020; Published online: 26 February 2020

\section{References}

1. Fagnoni, M., Dondi, D., Ravelli, D. \& Albini, A. Photocatalysis for the formation of the C-C bond. Chem. Rev. 107, 2725-2756 (2007).

2. Hoffmann, N. Photochemical reactions as key steps in organic synthesis. Chem. Rev. 108, 1052-1103 (2008).

3. Ravelli, D., Fagnoni, M. \& Albini, A. Photoorganocatalysis. what for? Chem. Soc. Rev. 42, 97-113 (2013).

4. Prier, C. K., Rankic, D. A. \& MacMillan, D. W. C. Visible light photoredox catalysis with transition metal complexes: applications in organic synthesis. Chem. Rev. 113, 5322-5363 (2013).

5. Schultz, D. M. \& Yoon, T. P. Solar synthesis: prospects in visible light photocatalysis. Science 343, 1239176 (2014).

6. Knoll, J. D., Albani, B. A. \& Turro, C. New Ru(II) complexes for dual photoreactivity: ligand exchange and ${ }^{1} \mathrm{O}_{2}$ generation. Acc. Chem. Res. 48, 2280-2287 (2015).

7. Ladomenou, K. et al. Photochemical hydrogen generation with porphyrinbased systems. Coord. Chem. Rev. 304-305, 38-54 (2015).

8. Urbani, M., de la Torre, G., Nazeeruddin, M. K. \& Torres, T. Phthalocyanines and porphyrinoid analogues as hole- and electron-transporting materials for perovskite solar cells. Chem. Soc. Rev. 48, 2738-2766 (2019).

9. Ke, X.-S. et al. Porphodilactones as synthetic chlorophylls: relative orientation of $\beta$-substituents on a pyrrolic ring tunes NIR absorption. J. Am. Chem. Soc. 136, 9598-9607 (2014).

10. Qi, Q. et al. Preferential binding of $\pi$-ligand porphyrin targeting $5^{\prime}-5^{\prime}$ stacking interface of human telomeric RNA G-quadruplex dimer. J. Phys. Chem. Lett. 10, 2143-2150 (2019).

11. Lu, H. \& Kobayashi, N. Optically active porphyrin and phthalocyanine systems. Chem. Rev. 116, 6184-6261 (2016).

12. Dąbrowski, J. M. et al. Engineering of relevant photodynamic processes through structural modifications of metallotetrapyrrolic photosensitizers. Coord. Chem. Rev. 325, 67-101 (2016).

13. Xiao, J.-D. \& Jiang, H.-L. Metal-organic frameworks for photocatalysis and photothermal catalysis. Acc. Chem. Res. 52, 356-366 (2019). 
14. He, W.-L., Zhao, M. \& Wu, C.-D. A versatile metalloporphyrinic framework platform for highly efficient bioinspired, photo- and asymmetric catalysis. Angew. Chem. Int. Ed. 58, 168-172 (2019).

15. Liu, Y., Howarth, A. J., Hupp, J. T. \& Farha, O. K. Selective photooxidation of a mustard-gas simulant catalyzed by a porphyrinic metal-organic framework. Angew. Chem. Int. Ed. 54, 9001-9005 (2015).

16. Ding, X. \& Han, B.-H. Metallophthalocyanine-based conjugated microporous polymers as highly efficient photosensitizers for singlet oxygen generation. Angew. Chem. Int. Ed. 54, 6536-6539 (2015).

17. Das, M. C., Xiang, S., Zhang, Z. \& Chen, B. Functional mixed metal-organic frameworks with metalloligands. Angew. Chem. Int. Ed. 50, 10510-10520 (2011).

18. Chen, R. et al. Designed synthesis of a $2 \mathrm{D}$ porphyrin-based $\mathrm{sp}^{2}$ carbonconjugated covalent organic framework for heterogeneous photocatalysis. Angew. Chem. Int. Ed. 58, 6430-6434 (2019).

19. Tranchemontagne, D. J., Ni, Z., O'Keeffe, M. \& Yaghi, O. M. Reticular chemistry of metal-organic polyhedra. Angew. Chem. Int. Ed. 47, 5136-5147 (2008).

20. Saha, M. L., Yan, X. \& Stang, P. J. Photophysical properties of organoplatinum (ii) compounds and derived self-assembled metallacycles and metallacages: fluorescence and its applications. Acc. Chem. Res. 49, 2527-2539 (2016).

21. Li, J.-R. \& Zhou, H.-C. Bridging-ligand-substitution strategy for the preparation of metal-organic polyhedra. Nat. Chem. 2, 893-898 (2010).

22. Zhang, D., Ronson, T. K. \& Nitschke, J. R. Functional capsules via subcomponent self-assembly. Acc. Chem. Res. 51, 2423-2436 (2018).

23. Jing, X., He, C., Zhao, L. \& Duan, C. Photochemical properties of host-guest supramolecular systems with structurally confined metal-organic capsules. Acc. Chem. Res. 52, 100-109 (2019).

24. Chen, L., Chen, Q., Wu, M., Jiang, F. \& Hong, M. Controllable coordinationdriven self-assembly: from discrete metallocages to infinite cage-based frameworks. Acc. Chem. Res. 48, 201-210 (2015).

25. Gong, W. et al. Permanent porous hydrogen-bonded frameworks with two types of Brønsted acid sites for heterogeneous asymmetric catalysis. Nat. Commun. 10, 600 (2019).

26. Yan, X., Cook, T. R., Wang, P., Huang, F. \& Stang, P. J. Highly emissive platinum(II) metallacages. Nat. Chem. 7, 342-348 (2015).

27. Hasell, T. \& Cooper, A. I. Porous organic cages: soluble, modular and molecular pores. Nat. Rev. Mater. 1, 16053 (2016).

28. Ke, X.-S. et al. Three-dimensional fully conjugated carbaporphyrin cage. J. Am. Chem. Soc. 140, 16455-16459 (2018).

29. Mastalerz, M. Porous shape-persistent organic cage compounds of different size, geometry, and function. Acc. Chem. Res. 51, 2411-2422 (2018).

30. $\mathrm{Qu}, \mathrm{H}$. et al. Molecular face-rotating cube with emergent chiral and fluorescence properties. J. Am. Chem. Soc. 139, 18142-18145 (2017).

31. Han, B. et al. Postsynthetic metalation of a robust hydrogen-bonded organic framework for heterogeneous catalysis. J. Am. Chem. Soc. 141, 8737-8740 (2019).

32. Mukhopadhyay, R. D., Kim, Y., Koo, J. \& Kim, K. Porphyrin boxes. Acc. Chem. Res. 51, 2730-2738 (2018).

33. Jones, J. T. A. et al. Modular and predictable assembly of porous organic molecular crystals. Nature 474, 367-371 (2011).

34. Bera, S. et al. Porosity switching in polymorphic porous organic cages with exceptional chemical stability. Angew. Chem. Int. Ed. 58, 4243-4247 (2019).

35. Smith, P. T. et al. Iron porphyrins embedded into a supramolecular porous organic cage for electrochemical $\mathrm{CO}_{2}$ reduction in water. Angew. Chem. Int. Ed. 57, 9684-9688 (2018).

36. Hong, S. et al. Porphyrin boxes: rationally designed porous organic cages Angew. Chem. Int. Ed. 54, 13241-13244 (2015).

37. Wang, Z. et al. Soft porous crystal based upon organic cages that exhibit guestinduced breathing and selective gas separation. J. Am. Chem. Soc. 141, 9408-9414 (2019).

38. Liu, Y., Hu, C., Comotti, A. \& Ward, M. D. Supramolecular archimedean cages assembled with 72 hydrogen bonds. Science 333, 436-400 (2011).

39. Rebek, J. Molecular behavior in small spaces. Acc. Chem. Res. 42, 1660-1668 (2009).

40. Omagari, T., Suzuki, A., Akita, M. \& Yoshizawa, M. Efficient catalytic epoxidation in water by axial $\mathrm{n}$-ligand-free $\mathrm{Mn}$-porphyrins within a micellar capsule. J. Am. Chem. Soc. 138, 499-502 (2016).

41. Shi, Y. et al. Selective extraction of $\mathrm{C} 70$ by a tetragonal prismatic porphyrin cage. J. Am. Chem. Soc. 140, 13835-13842 (2018).

42. Cremers, J. et al. Template-directed synthesis of a conjugated zinc porphyrin nanoball. J. Am. Chem. Soc. 140, 5352-5355 (2018).

43. Benke, B. P. et al. Iodide-selective synthetic ion channels based on shapepersistent organic cages. J. Am. Chem. Soc. 139, 7432-7435 (2017).

44. Ward, M. D., Hunter, C. A. \& Williams, N. H. Coordination cages based on bis(pyrazolylpyridine) ligands: structures, dynamic behavior, guest binding, and catalysis. Acc. Chem. Res. 51, 2073-2082 (2018).

45. Oliveri, C. G. et al. Supramolecular allosteric cofacial porphyrin complexes. J. Am. Chem. Soc. 128, 16286-16296 (2006).
46. Fiedler, D., Leung, D. H., Bergman, R. G. \& Raymond, K. N. Selective molecular recognition, $\mathrm{C}-\mathrm{H}$ bond activation, and catalysis in nanoscale reaction vessels. Acc. Chem. Res. 38, 349-358 (2005).

47. Inokuma, Y. et al. X-ray analysis on the nanogram to microgram scale using porous complexes. Nature 495, 461-466 (2013).

48. Iwasawa, T., Hooley, R. J. \& Rebek, J. Stabilization of labile carbonyl addition intermediates by a synthetic receptor. Science 317, 493-496 (2007).

49. Yoshizawa, M., Tamura, M. \& Fujita, M. Diels-alder in aqueous molecular hosts: unusual regioselectivity and efficient catalysis. Science 312, 251-254 (2006).

50. Pluth, M. D., Bergman, R. G. \& Raymond, K. N. Acid catalysis in basic solution: a supramolecular host promotes orthoformate hydrolysis. Science 316, 85-88 (2007).

51. Wang, Q.-Q. et al. Self-assembled nanospheres with multiple endohedral binding sites pre-organize catalysts and substrates for highly efficient reactions. Nat. Chem. 8, 225-230 (2016).

52. Yang, X., Sun, J.-K., Kitta, M., Pang, H. \& Xu, Q. Encapsulating highly catalytically active metal nanoclusters inside porous organic cages. Nat. Catal. 1, 214-220 (2018)

53. Kim, Y. et al. Rational design and construction of hierarchical superstructures using shape-persistent organic cages: porphyrin box-based metallosupramolecular assemblies. J. Am. Chem. Soc. 140, 14547-14551 (2018).

54. Pan, M., Wu, K., Zhang, J.-H. \& Su, C.-Y. Chiral metal-organic cages/ containers (MOCs): from structural and stereochemical design to applications. Coord. Chem. Rev. 378, 333-349 (2019).

55. Zhang, Z. et al. Aqueous platinum(ii)-cage-based light-harvesting system for photocatalytic cross-coupling hydrogen evolution reaction. Angew. Chem. Int. Ed. 58, 8862-8866 (2019).

56. Slater, A. G. et al. Reticular synthesis of porous molecular 1D nanotubes and 3D networks. Nat. Chem. 9, 17-25 (2016).

57. Miao, X. et al. Deciphering the intersystem crossing in near-infrared BODIPY photosensitizers for highly efficient photodynamic therapy. Chem. Sci. 10, 3096-3102 (2019).

58. Andréasson, J., Kajanus, J., Mårtensson, J. \& Albinsson, B. Triplet energy transfer in porphyrin dimers: comparison between $\pi$ - and $\sigma$-chromophore bridged systems. J. Am. Chem. Soc. 122, 9844-9845 (2000).

59. Zhang, X.-F., Yang, X. \& Xu, B. PET-based bisBODIPY photosensitizers for highly efficient excited triplet state and singlet oxygen generation: tuning photosensitizing ability by dihedral angles. Phys. Chem. Chem. Phys. 19, 24792-24804 (2017).

60. Bachilo, S. M. \& Weisman, R. B. Determination of triplet quantum yields from triplet-triplet annihilation fluorescence. J. Phys. Chem. A 104, 7711-7714 (2000).

61. Šolomek, T. et al. Electron hopping and charge separation within a naphthalene-1,4:5,8-bis(dicarboximide) chiral covalent organic cage. J. Am. Chem. Soc. 139, 3348-3351 (2017).

62. Ma, L. et al. Ferrocene-linkage-facilitated charge separation in conjugated microporous polymers. Angew. Chem. Int. Ed. 58, 4221-4226 (2019).

63. Luo, J., Lu, J. \& Zhang, J. Carbazole-triazine based donor-acceptor porous organic frameworks for efficient visible-light photocatalytic aerobic oxidation reactions. J. Mater. Chem. A 6, 15154-15161 (2018).

64. Shao, W. et al. Photophysical properties and singlet oxygen generation of three sets of halogenated corroles. J. Phys. Chem. B 116, 14228-14234 (2012).

65. Murahashi, S.-I. Synthetic aspects of metal-catalyzed oxidations of amines and related reactions. Angew. Chem. Int. Ed. 34, 2443-2465 (1995).

66. Feng, D. et al. Zirconium-metalloporphyrin PCN-222: mesoporous metal-organic frameworks with ultrahigh stability as biomimetic catalysts. Angew. Chem. Int. Ed. 51, 10307-10310 (2012).

67. Morris, W. et al. Synthesis, structure, and metalation of two new highly porous zirconium metal-organic frameworks. Inorg. Chem. 51, 6443-6445 (2012).

68. Feng, D. et al. Construction of ultrastable porphyrin $\mathrm{Zr}$ metal-organic frameworks through linker elimination. J. Am. Chem. Soc. 135, 17105-17110 (2013).

69. Fickling, M. M., Fischer, A., Mann, B. R., Packer, J. \& Vaughan, J. Hammett substituent constants for electron-withdrawing substituents: dissociation of phenols, anilinium ions and dimethylanilinium ions. J. Am. Chem. Soc. 81, 4226-4230 (1959).

70. Senge, M. O. et al. Synthesis of meso-substituted ABCD-type porphyrins by functionalization reactions. Eur. J. Org. Chem. 2010, 237-258 (2010).

\section{Acknowledgements}

Financial support from the Natural Science Foundation of China (Nos. 21631003, 21805005, and 21425313), the Fundamental Research Funds for the Central Universities (No. FRF-BD-17-016A), Welch Foundation (AX-1730), National Science Foundation (DMR1606826), and University of Science and Technology Beijing is gratefully acknowledged. 


\section{Author contributions}

C.L. and H.W. performed experiments; J.J., B.C., H.W., and C.L. conceived and supervised the project; C.W. performed theoretical calculations; K.L., H.L., H.S., and X.L. performed the nanosecond transient absorption spectroscopy and analysis; J.J., B.C., H.W., and C.L. linked experiments and analysis; and all the authors discussed and wrote the manuscript.

\section{Competing interests}

The authors declare no competing interests.

\section{Additional information}

Supplementary information is available for this paper at https://doi.org/10.1038/s41467020-14831-x.

Correspondence and requests for materials should be addressed to H.W., B.C. or J.J.

Peer review information Nature Communications thanks Marta Liras and the other anonymous reviewer for their contribution to the peer review of this work.
Reprints and permission information is available at http://www.nature.com/reprints

Publisher's note Springer Nature remains neutral with regard to jurisdictional claims in published maps and institutional affiliations.

(c) Open Access This article is licensed under a Creative Commons Attribution 4.0 International License, which permits use, sharing, adaptation, distribution and reproduction in any medium or format, as long as you give appropriate credit to the original author(s) and the source, provide a link to the Creative Commons license, and indicate if changes were made. The images or other third party material in this article are included in the article's Creative Commons license, unless indicated otherwise in a credit line to the material. If material is not included in the article's Creative Commons license and your intended use is not permitted by statutory regulation or exceeds the permitted use, you will need to obtain permission directly from the copyright holder. To view a copy of this license, visit http://creativecommons.org/licenses/by/4.0/.

(C) The Author(s) 2020 